\title{
Density-Dependent Predation of a Dominant Species does not Facilitate Increased Diversity in Treeholes
}

\author{
Leslie M. Smith, Jarrod Blue, Jessica Carlson, Grace Metz, Joshua Haywood, Daniel Bush and \\ Christopher J. Paradise ${ }^{*}$
}

Biology Department, Davidson College, Davidson, NC 28035-7118, USA

\begin{abstract}
The effects of predation on water-filled treehole communities in North Carolina were examined using mesocosm experiments and observations in natural treeholes. The presence of the predator Toxorhynchites rutilus and leaf litter abundance were manipulated in mesocosms to examine interactions between resources and predation. Long-term examination of interactions in unmanipulated treeholes provided data on natural variation in water volume and predator density. Toxorhynchites rutilus preys upon two common treehole insects, Aedes triseriatus and Culicoides guttipennis. We predicted that $T$. rutilus would act as a keystone predator and reduce the density of these dominant species. This would allow other species to coexist and lead to an increase in diversity. We also predicted that effects of predation would be reduced in habitats with high levels of resources, due to either increased refugia or decreased competition. The results did not entirely support the predictions. In both mesocosms and treeholes T. rutilus depressed densities of the most abundant prey type, A. triseriatus. In treeholes, the presence of $T$. rutilus depressed densities of the midge $C$. guttipennis, and predator densities were positively associated with insect diversity in treeholes. Strikingly, higher diversity was also associated with high densities of the dominant prey in treeholes. In addition, mesocosms showed no relationship between T. rutilus presence and species diversity. The relationship between the predator and diversity in treeholes appears to be unrelated to predation on the dominant competitors and is instead caused by some other habitat characteristic. While there were effects of resources on densities and diversity in both mesocosms and treeholes, neither of the resources analyzed, leaf litter or water, appear to be the sole characteristic that mutually allows for large populations of T. rutilus and high species diversity. We conclude that though T. rutilus is an aggressive predator, it does not cause an increase in prey species diversity as a keystone predator would. Further research is needed to determine the conditions that favor the presence of predator and high prey diversity.
\end{abstract}

Keywords: Aedes triseriatus, Culicoides guttipennis, diversity, habitat volume, keystone species, predation, resources, Toxorhynchites rutilus, treehole.

\section{INTRODUCTION}

Predation can have wide-ranging direct and indirect effects on ecological communities. Direct effects include consumption of prey, alterations of prey behavior, and negative growth rates of prey populations (Abrams et al. 1996, Peacor and Werner 2001, Schmitz and Suttle 2001). Induced changes in prey behavior can lower the foraging efficiency of competitively dominant species and release pressure on competitors (Peacor and Werner 2001). This indirect predation effect perpetuates through the ecosystem causing an increase in species diversity (Abrams et al. 1996, Peacor and Werner 2001, Schmitz and Suttle 2001). Typically, species that cause this indirect effect are categorized as keystone predators, a predator whose presence causes a decrease in the density or abundance of a competitively dominant species, indirectly increasing species diversity as competitively inferior species that are able to establish populations (Paine 1969). In cases where there are

*Address correspondence to this author at the Biology Department, Box 7118, Davidson College, Davidson, NC, 28035, USA; Tel: (704) 894-2890, Fax: (704) 894-2512; E-mail: chparadise@davidson.edu

Handling Editor: Dr. Frank Johansson very few levels of the food chain, indirect changes can have large effects on community structure (Abrams et al. 1996).

Resources and habitat availability can also have direct and indirect effects on consumers (Sota 1996, Yanoviak 1999, Paradise 2004). The amount of resources present can reduce negative impacts of predators by reducing competition among prey species and allowing individuals and populations to grow more quickly even in the presence of predators. Thus the outcome of predation depends upon the relative amounts of predation and resources (Batzer 1998, Rosemond et al. 2001, Kneitel and Miller 2002). The amount of available habitat may also provide large numbers of refugia or increase habitat heterogeneity, decreasing predation effects by increasing growth rates of prey populations or decreasing efficiency of prey capture (Kitching 2000, Costanzo et al. 2005). Prey species with altered behavior in the presence of the predator or wider habitat preferences than predators are known factors affecting survival of prey species in local communities and in the metacommunity (Juliano and Gravel 2002, Paradise 2004, Paradise et al. 2008). The ability of prey to escape from predation within and between habitats allows regional coexistence of predator and prey in a metacommunity. Such regional coexistence has 
been demonstrated in treehole metacommunities (Ellis et al. 2006, Paradise et al. 2008).

The predatory treehole mosquito, Toxorhynchites rutilus (Coquillet), is the top predator of treeholes in Southeastern North America (Bradshaw and Holzapfel 1983). Treeholes are water-filled container communities with a detritus-based food web of larval insects, protists, and microbes (Kitching 2000). Among the insect inhabitants of the North Carolina treeholes are several species of mosquitoes (O. Diptera, F. Culicidae) including the eastern treehole mosquito Aedes triseriatus (Say) and the invasive A. albopictus (Skuse). Aedes triseriatus is the numerically dominant insect in treeholes in the Eastern United States (Paradise 2004, Harlan and Paradise 2006, Paradise et al. 2008). The second most abundant species is the ceratopogonid midge Culicoides guttipennis (Coquillet).

The larvae of $T$. rutilus are size-selective predators that hunt prey in the water column (Bradshaw and Holzapfel 1983, Juliano and Gravel 2002). Active prey, such as $A$. triseriatus, that feed more frequently in the open water and are numerically dominant are at high risk of predation (Bradshaw and Holzapfel 1983, Juliano 1989, Juliano and Gravel 2002). Studies have found that T. rutilus directly reduces the populations of mosquitoes, possibly causing local extinction and reducing competition (Fish and Carpenter 1982, Juliano 1989, Barrera 1996). The absence of T. rutilus has also been shown to directly lead to high population density and numerical dominance of $A$. triseriatus (Steffan and Evenhuis 1981, Bradshaw and Holzapfel 1983, Sota 1996, Lounibos et al. 1997).

Indirect effects of predation, in terms of the impact of reduction of a dominant species on the overall community, are difficult to observe in an unmanipulated experiment. Toxorhynchites rutilus females tend to oviposit in larger treeholes due to their non-drought-resistant eggs (Steffan and Evenhuis 1981, Bradshaw and Holzapfel 1983, Lounibos et al. 1997, Lounibos 2001). Large, long-lasting treeholes have more productivity, resources and microhabitats, and may support more individuals and higher diversity than small treeholes, regardless of whether they are inhabited by $T$. rutilus (Bradshaw and Holzapfel 1983, Jenkins and Kitching 1990, Sota et al. 1994, Sota 1996, Paradise 2004). As such, an increase in less dominant prey species could be due to increased oviposition by those species in larger habitats, rather than an indirect effect of predation on dominant prey species. Although it has been suggested that T. rutilus is a keystone predator (Kitching 2000) there is not much evidence to support that contention. To our knowledge there have been no experiments on manipulations in the presence or absence of this predator to test the keystone species hypothesis in treeholes.

We predicted that $T$. rutilus would have direct effects on numerically dominant prey populations as well as less abundant prey species that frequent open water, in both manipulated mesocosms and unmanipulated treeholes. We also predicted that depletion of populations of numerically dominant species, through predation, would allow other species to successfully inhabit local communities, increasing prey species diversity. We further predicted that the effects of $T$. rutilus would be reduced in habitats with high resource availability (either water or leaf litter) due to either increased refugia or decreased competition. We tested these predictions in an observational study of treeholes and a manipulative field mesocosm experiment where both leaf litter abundance and the presence of the predator were independent variables.

\section{METHODS}

We used two approaches to investigate the impact of $T$. rutilus across time and space. We monitored treeholes to capture the dynamics of unmanipulated communities. We also performed a mesocosm experiment where we held water volume constant and independently varied the presence of the predator and the amount of leaf litter resources to determine direct and indirect effects of predation and interactive effects of predation with resource abundance.

\section{Treeholes}

We monitored treeholes found in the Davidson College Ecological Preserve (DCEP, Davidson, NC; $35^{\circ} 30^{\prime} 37^{\prime \prime} \mathrm{N}$, $\left.80^{\circ} 49^{\prime} 48^{\prime} \mathrm{W}\right)$ and the Davidson College Lake Campus (DCLC, Mt. Mourne, NC, centered on $35^{\circ} 31^{\prime} 48^{\prime \prime} \mathrm{N}, 80^{\circ}$ 52' 58" W), in the North Carolina Piedmont region (see Fig. S1 in Supplementary Material for treehole photos). Treeholes were visited monthly during periods of insect activity in 2004, 2005, and 2006 to monitor insect populations and resources. Volume of individual treeholes ranged from 200 to over 7,500 $\mathrm{mL}$, water volumes ranged from 0 to $7,000 \mathrm{~mL}$, and wet mass of leaf litter ranged from 0 to $250 \mathrm{~g}$. Twenty treeholes were sampled monthly in 2004; sixteen of those and thirteen others were monitored monthly in 2005 and 2006.

During monitoring, water was removed with a baster and placed into a large plastic beaker to measure the volume; leaf litter was removed and placed into a separate tared plastic beaker. Leaf litter was weighed on a portable digital balance; however, leaf litter data were not used in the analysis because leaf litter did not accumulate in many treeholes and what was present tend to degrade to sediment by late summer. Water and leaf litter contents were examined by spreading each out in separate white trays in the field. All insect larvae were identified to species and developmental stage, and counted. Early instar larvae of some species of mosquitoes were difficult to distinguish and were pooled. Through rearing mosquito larvae to adults in our study area we determined that $90 \%$ of mosquito larvae were $A$. triseriatus. A small sample of sediment was also taken from each treehole and examined for insects. Distilled water was used sparingly to rinse off leaf litter and spread sediment in order to search for organisms. All material was placed back into each treehole in the reverse order from which it was extracted.

\section{Predator Manipulation in Mesocosms}

Mesocosms were constructed and deployed during early spring 2005. Mesocosms were constructed out of PVC pipe with a $7.62 \mathrm{~cm}$ internal diameter cut into $11 \mathrm{~cm}$ lengths, yielding a capacity of $540 \mathrm{~mL}$ (see Fig. S1 in Supplementary Material for mesocosm photos). Fiberglass window screening was used to line inside of the PVC pipe. The screen was held in place at the top with a sawed-in-half PVC 
coupling and aquarium caulk. Caulk was also used to seal the screen and an end cap at the bottom. The screen provided a rough texture and darker interior than the pipe alone.

Mesocosms were attached to frames made from $1.5 \mathrm{~cm}$ PVC pipe. Pairs of mesocosms were attached to a frame and bound together using expandable polyurethane foam. Frames were tied to trees in a hardwood forest on the Davidson College Ecological Preserve. A fiberglass window screen (2 $\mathrm{mm}$ mesh) was glued to the top of each frame, $25 \mathrm{~cm}$ above the mesocosms, to reduce debris from entering mesocosms. Each frame and the trunk of its tree were wrapped in $2.5 \mathrm{~cm}$ mesh chicken wire, with a door cut into it for access.

We employed a two-factor fully crossed design with 10 replicates of each treatment combination in 2005 and 5 replicates in 2007 (in 2007, one mesocosm from each of the pairs used in 2005 was randomly selected). The two factors were quantity of leaf litter (dried white oak leaves: Quercus alba L.) and presence/absence of $T$. rutilus, each with two levels (leaf litter (LL): 3 and $8 \mathrm{~g} / \mathrm{L} ;$ T. rutilus presence (Tx): 0 and $1+)$. Treatments were randomly assigned to each mesocosm.

We added leaf litter in late May and T. rutilus three weeks later. We checked mesocosms for T. rutilus eggs every other day. Toxorhynchites rutilus eggs are easily identifiable by their oval shape, white coloration, and location on the water surface (Steffan and Evenhuis 1981). Anything found was brought back to the laboratory. Removal of eggs from all mesocosms allowed for control of predator presence and density. Any eggs collected were reared to $2^{\text {nd }}$ instar larvae in the laboratory in individual 20 $\mathrm{mL}$ vials, where they were maintained on $1^{\text {st }}$ instar larvae of prey mosquitoes.

Monitoring occurred every two weeks from July through August 2005, and June through July 2007 to determine the abundance and stages of all residents. Each census was completed within a two day period. Contents of containers were examined using the same methods used for treeholes. The exception was that we rinsed the sides of mesocosms with a small amount of distilled water to remove any organisms and detritus clinging to the sides or bottom. This water was then removed and added to the extracted water. The additional water was used to bring volume back to the nominal value. The experiment ended each year when we stopped finding $T$. rutilus eggs.

After each count, the state of $T$. rutilus in predator mesocosms was assessed. Ideally, predator mesocosms had one individual predator continuously during the experiment. Our previous experience was that one larva was sufficient in that size container to have a large impact, and more than one might lead to intraspecific predation. Any predator mesocosm that had no predator (due to mortality or emergence) or had only a pupa present, received a new $2^{\text {nd }}$ instar T. rutilus the following day. Any mesocosm designated to have a predator present that had a $4^{\text {th }}$ instar T. rutilus received a new $2^{\text {nd }}$ instar T. rutilus the following week, which allowed time for the $4^{\text {th }}$ instar individual to pupate. This delay prevented cannibalism of $2^{\text {nd }}$ instar individuals by older larvae.

In some cases, mesocosms designated to be free of $T$. rutilus had a larva present during a census. When these unwanted larvae were found, they were removed; however, they had often grown substantially by that point. In 2005, 11 of 20 predator-free mesocosms never had a predator (three with high leaf litter and eight with low leaf litter). In 2007, 10 out of 10 predator-free mesocosms never had a predator. All predator mesocosms consistently had one or two individual $T$. rutilus throughout the experiment.

\section{ANALYSIS}

We took into account the developmental stage of both $A$. triseriatus and T. rutilus in analysis of both treeholes and mesocosms. Because T. rutilus is a size selective predator, we divided the most common prey type, mosquitoes, into two groups: $1^{\text {st }}$ and $2^{\text {nd }}$ instars and $3^{\text {rd }}$ instars-pupae. The developmental stage of T. rutilus was also important as a $4^{\text {th }}$ instar T. rutilus has been in a treehole significantly longer and has had a potentially larger impact on the community than one in the $2^{\text {nd }}$ instar. When a $1^{\text {st }}$ or $2^{\text {nd }}$ instar T. rutilus was found in a treehole census, presence of $T$. rutilus was credited to the next census regardless of whether a predator was found in that later census. We justified doing this because of the high survivorship of T. rutilus (Lounibos et al. 1987, Lounibos 2001, L.M. Smith, personal observation), which makes it likely that the $1^{\text {st }}$ or $2^{\text {nd }}$ instar survived to pupation, and the small impact that a $1^{\text {st }}$ or $2^{\text {nd }}$ instar $T$. rutilus has based on its lower consumption and shorter inhabitation time. Based on these guidelines, we used either presence/absence of $T$. rutilus or its density for analysis, depending on the test.

Natural treehole data were analyzed by using regression analysis. Mesocosm data were analyzed using both randomization regressions and profile analysis. We considered using path analysis to test for direct and indirect effects, but rejected it because our treehole data failed to meet assumptions of independence. Averaging responses over time for each treehole was not a solution because of wide seasonal variations and inconsistency of presence of the predator in treeholes. We decided on randomization regressions because that allowed us to use data over time despite the non-independence issue. While this makes it more difficult to separate direct and indirect effects, by analyzing relationships among several variables, we were able to infer potential indirect effects.

\section{Predator Manipulation Profile Analysis}

To analyze mesocosm data we conducted a multivariate analysis of variance (MANOVA) profile analysis for repeated measures (von Ende 2001) to test the effects of leaf litter levels and the presence of $T$. rutilus on early instar mosquito $\left(1^{\text {st }}\right.$ and $2^{\text {nd }}$ instars) densities, late instar mosquito ( $3^{\text {rd }}$ instars-pupae) densities, C. guttipennis densities, and prey species diversity. Diversity was calculated as e (base of the natural logarithm) raised to the power of the Shannon diversity index, $\mathrm{H}^{\prime}=-\Sigma\left(\mathrm{p}_{\mathrm{i}} \cdot \ln \left(\mathrm{p}_{\mathrm{i}}\right)\right)$, known as the effective species richness (Jost 2006). Profile analysis is used for repeated measures data because it transforms the withinsubject repeated measures data to a set of contrasts, or differences, either over time or across treatments (von Ende 2001). In this analysis, leaf litter quantity and T. rutilus presence were fixed effects factors. Differences and averages from consecutive censuses became transformed variables in 
two-way MANOVAs, used to test for interactions and main effects, respectively. The experiment-wise $\alpha$ of 0.05 was adjusted to 0.0125 to account for the number of profile analyses performed.

We used only mesocosms that consistently did not have a predator and mesocosms that consistently had a predator. For 2005 data, we did not use the final census because it was the end of the season and there were very few larvae present. Although treeholes were also sampled repeatedly, we could not use a profile analysis because consistent application of the treatments across censuses was required and the presence of $T$. rutilus in any one treehole was inconsistent.

\section{Randomization Tests}

We tested for a relationship between the two prey types, combined $3^{\text {rd }}$ instars - pupae $A$. triseriatus and $C$. guttipennis, and the predatory mosquito, T. rutilus. We performed randomization regressions on log-transformed densities of prey and predator for any treehole in which we found the prey, the predator, or both using data pooled across all three years. We also ran regressions to test for the effect of $T$. rutilus density and water volume on species diversity, each of the two most common prey types on diversity, and water volume on $T$. rutilus density, again using data pooled across years. We used water volume because previous research (Sota et al. 1994, Sota 1996, Paradise 2004) indicates that water volume is an important predictor of treehole communities. Ovipositing females can likely assess surface area, but this same research does not clearly support a relationship between density or diversity with surface area. For mesocosm data, we tested for a relationship of $T$. rutilus density on the density of each prey type, and $T$. rutilus density, leaf litter mass, and two common prey densities $(A$. triseriatus and $C$. guttipennis) on species diversity. Randomization tests were performed using RT: A Program for Randomization Testing (v. 2.1, Manly, 1997), with significance calculated by using 10,000 randomizations (Manly 1997). Prior to performing regressions, we analyzed the data for normality and homogeneity of variance, and log-transformed densities and water volume.

\section{RESULTS}

Early instar mosquitoes were not affected by the presence of the predator (Table 1, Figs. 1a, 2a and c). Late instar and pupae mosquito density were depressed by $T$. rutilus in treeholes as well as mesocosms in both 2005 and 2007 (Tables $\mathbf{1}$ and 2, Figs. 1b, $\mathbf{2 b}$ and d). Toxorhynchites rutilus significantly decreased $C$. guttipennis density in treeholes, but not in mesocosms in either year (Tables 1 and 2, Figs. 1c and 3). The depression of prey densities in treeholes was not consistent over time (Figs. $\mathbf{1 b}$ and $\mathbf{c}$ ). There were no effects of leaf litter mass on the densities of mosquitoes and $C$. guttipennis.

Table 1. Results of Profile Analysis in Predator Manipulation Mesocosm Experiment, Using Data from July 7 through August 24, 2005 and May 29 through July 23, 2007. Significant $\underline{P}$ Values are in Boldface Type

\begin{tabular}{|c|c|c|c|c|c|c|c|c|}
\hline \multirow[t]{2}{*}{ Variable } & \multicolumn{2}{|c|}{$\begin{array}{c}\text { Early Instar Prey } \\
\text { Mosquitoes }\end{array}$} & \multicolumn{2}{|c|}{$\begin{array}{l}\text { Late Instar Prey } \\
\text { Mosquitoes }\end{array}$} & \multicolumn{2}{|c|}{ Midges } & \multicolumn{2}{|c|}{ Diversity } \\
\hline & $\lambda^{*}$ & $\underline{\mathbf{P}}^{\dagger}$ & $\lambda$ & $\underline{\mathbf{P}}$ & $\lambda$ & $\underline{\mathbf{P}}$ & $\lambda$ & $\underline{\mathbf{P}}$ \\
\hline \multicolumn{9}{|l|}{$2005^{\S}$} \\
\hline T. rutilus ${ }^{\ddagger}$ main effect & 0.84 & 0.21 & 0.66 & 0.01 & 0.86 & 0.27 & 0.91 & 0.50 \\
\hline Litter $x$ time & 0.96 & 0.79 & 0.90 & 0.43 & 0.78 & 0.10 & 0.88 & 0.36 \\
\hline T. rutilus $\mathrm{x}$ litter & 0.98 & 0.91 & 0.85 & 0.25 & 0.98 & 0.90 & 0.99 & 0.99 \\
\hline T. rutilus $\mathrm{x}$ litter $\mathrm{x}$ time & 0.96 & 0.82 & 0.96 & 0.80 & 0.89 & 0.40 & 0.99 & 0.99 \\
\hline \multicolumn{9}{|l|}{$2007^{\S}$} \\
\hline T. rutilus $\mathrm{x}$ time & 0.74 & 0.39 & 0.86 & 0.70 & 0.64 & 0.09 & 0.65 & 0.10 \\
\hline Litter $\mathrm{x}$ time & 0.89 & 0.81 & 0.82 & 0.59 & 0.51 & 0.02 & 0.70 & 0.16 \\
\hline T. rutilus $\mathrm{x}$ litter & 0.74 & 0.38 & 0.68 & 0.25 & 0.75 & 0.24 & 0.63 & 0.08 \\
\hline T. rutilus $\mathrm{x}$ litter $\mathrm{x}$ time & 0.70 & 0.29 & 0.75 & 0.39 & 0.69 & 0.15 & 0.74 & 0.22 \\
\hline
\end{tabular}

${ }^{*} \lambda=$ Wilk's lambda, the test statistic

${ }^{\dagger} \underline{P}=$ the probability that the null hypothesis is true; $\underline{\mathrm{P}} \leq 0.0125$ indicates a significant test result.

${ }^{\sharp} T$. rutilus $=$ presence/absence of the predator, and Litter $=$ leaf litter treatment.

${ }^{\S}$ Degrees of freedom $=3,25$ for all 2005 tests and 3, 14 for all 2007 tests. 
Table 2. Results of Randomization Regressions. (a) Regressions on Treehole Data. (b) Regressions on 2005 Mesocosm Data. (c) Regression on 2007 Mesocosm Data. Significant Regression $\underline{P}$ Values are in Boldface Type

\begin{tabular}{|c|c|c|c|c|c|c|}
\hline Regression (y vs. $x)$ & $\underline{\mathbf{F}}$ & $\underline{\text { df }}$ & $\underline{\mathbf{P}}$ & Slope & Y-int & $\underline{\mathbf{R}^{2}}$ \\
\hline \multicolumn{7}{|l|}{ a. Treeholes } \\
\hline Midges vs. T. rutilus & 99.08 & 1,253 & $<0.0001$ & $-1.19^{*}$ & 1.61 & 0.28 \\
\hline Diversity $v s . T$. rutilus and water volume & 17.52 & 1,398 & $<0.0001$ & $\begin{array}{c}0.33 * \\
-0.14\end{array}$ & 0.42 & 0.08 \\
\hline Diversity $v s$. mosquitoes & 8.63 & 1,399 & 0.003 & $0.071 *$ & 0.41 & 0.02 \\
\hline Diversity $v s$. midges & 51.06 & 1,399 & $<0.0001$ & $0.15^{*}$ & 0.33 & 0.11 \\
\hline \multicolumn{7}{|l|}{ b. Mesocosms (2005) } \\
\hline Mosquitoes $v s$. T. rutilus & 11.87 & 1,153 & 0.001 & $-0.34 *$ & 1.30 & 0.07 \\
\hline Diversity $v s$. mosquitoes & 0.51 & 1,153 & 0.47 & -0.034 & 0.54 & 0.003 \\
\hline Diversity $v s$. midges & 105.68 & 1,153 & $<0.0001$ & $0.33 *$ & 0.21 & 0.41 \\
\hline \multicolumn{7}{|l|}{ c. Mesocosms (2007) } \\
\hline Mosquitoes vs. T. rutilus & 16.07 & 1,98 & $<0.0001$ & $-0.40^{*}$ & 1.52 & 0.13 \\
\hline Midges vs. T. rutilus & 3.06 & 1,98 & 0.08 & -0.22 & 1.19 & 0.02 \\
\hline Diversity vs. T. rutilus and leaf litter & 1.30 & 2,97 & 0.28 & $\begin{array}{l}-0.048 \\
-0.015\end{array}$ & 0.55 & 0.006 \\
\hline Diversity $v s$. mosquitoes & 0.13 & 1,98 & 0.72 & 0.02 & 0.41 & 0.001 \\
\hline
\end{tabular}

${ }^{\dagger}$ Each row contains the results of a regression of dependent variable $v s$. independent variable.

"Significant slopes are marked with an asterisk.

Species richness in mesocosms and natural treeholes were comparable. A total number of nine insect species was found in mesocosms. In addition to the three species of mosquitoes and C. guttipennis, we found the scirtid beetle Helodes pulchella (Guerin), two syrphids (Mallota posticata (Fabricius) and Myiolepta sp.), the psychodid Telmatoscopus albipunctatus (Williston), and a dolichopodid (Systenus sp.). All species were also found in treeholes with the exception of the syrphid Myiolepta sp. Median species richness in mesocosms was greater than in treeholes with three and two species respectively. Maximum species richness (minus $T$. rutilus) in treeholes was greater than in mesocosms with eight and seven species, respectively, while the minimum for both was zero species.

The effect of predator presence on species diversity varied through time, but was observed in both mesocosms and natural treeholes. Predator presence was positively associated with diversity in mesocosms in 2007 but not in 2005 (Tables 1, 2b and 2c). The randomization regression revealed that in treeholes predator density had a significant positive relationship with diversity (Table $\mathbf{2 a}$; significant slope of T. rutilus in the diversity vs. T. rutilus and water volume regression), but predator density did not significantly affect prey diversity in mesocosms in either 2005 or 2007 (Tables $\mathbf{2 b}$ and $\mathbf{c}$ ).

Densities of mosquitoes and C. guttipennis both had a significant positive association with prey diversity in treeholes (Table 2a). Mosquito densities were not associated with higher insect diversity in mesocosm experiments. However, as midge densities increased, so did insect diversity, in every case (Table 2). These results run counter to our predictions that diversity would increase as dominant prey declined.

In terms of resources, the combined effect of predator density and water volume in treeholes significantly affected prey diversity. Taken separately, the slope coefficient of the randomization regression for diversity vs. water volume was not significant, and thus was not correlated to diversity by itself (Table 2a). At the same time, increased water volume was not associated with higher densities of the predator, suggesting that water volume does not determine predator densities. In mesocosms, the combined effects of predator 

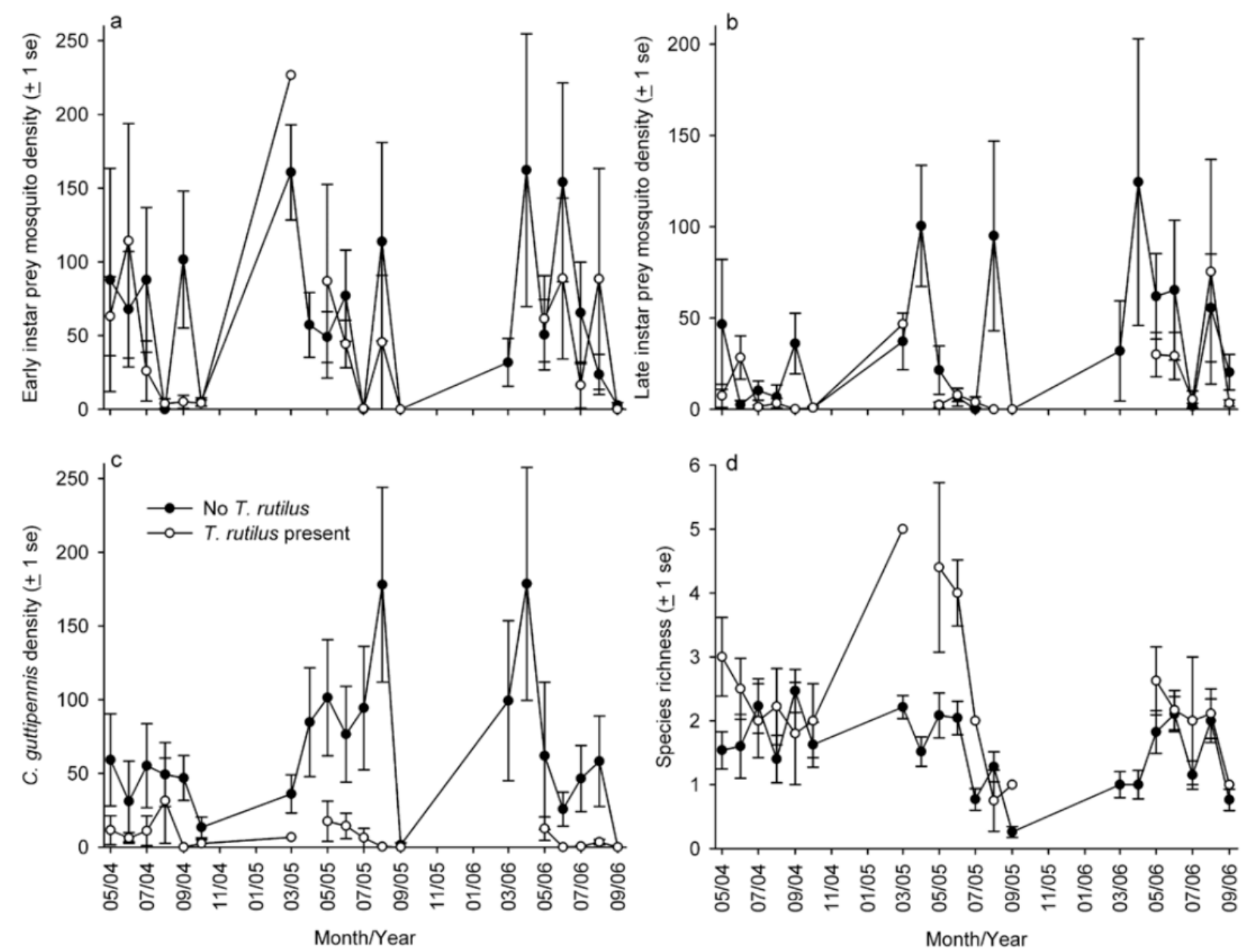

Fig. (1). The effects of T. rutilus on treehole insect prey by census. During some months, no T. rutilus were found in any treeholes, leading to the gaps in the T. rutilus profile. All points are means $+/-1$ standard error. a. First and second instar prey mosquito density. b. Third and fourth instar prey mosquito density. c. Culicoides guttipennis density. d. Effective species richness, not including T. rutilus ( $\mathrm{e}^{\mathrm{H}}$ ).
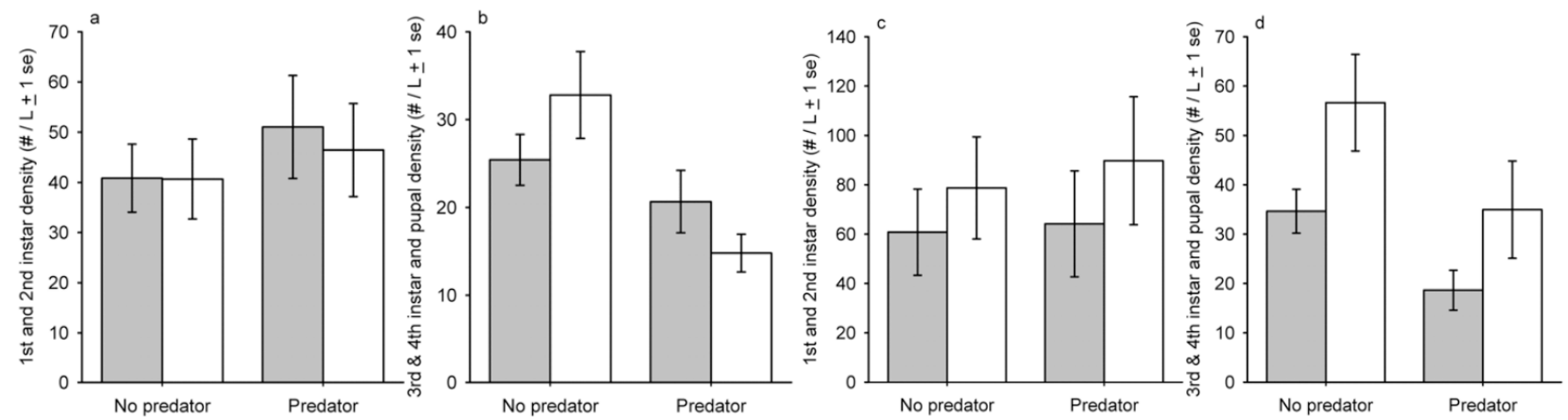

Fig. (2). Time-averaged densities of A. triseriatus in mesocosms during 2005 and 2007. a. Combined $1^{\text {st }}$ and $2^{\text {nd }}$ instar densities in 2005 . b. Combined $3^{\text {rd }}$ instar - pupae densities in 2005. c. Combined $1^{\text {st }}$ and $2^{\text {nd }}$ instar densities in 2007. d. Combined $3^{\text {rd }}$ instar - pupae densities in 2007. Grey bars represent low leaf litter treatments and open bars represent high leaf litter treatments. Error bars represent 1 standard error.

density and leaf litter abundance were significant predictors of prey diversity in 2005 but not in 2007 (Tables $\mathbf{2 b}$ and $\mathbf{c}$ ). Leaf litter abundance had a significantly positive effect on diversity only in 2005 mesocosms (Table $\mathbf{2 b}$ ).

\section{DISCUSSION}

As predicted, T. rutilus had direct effects on densities of the dominant prey species. The effects of $T$. rutilus on populations of $A$. triseriatus were strong but not consistent 

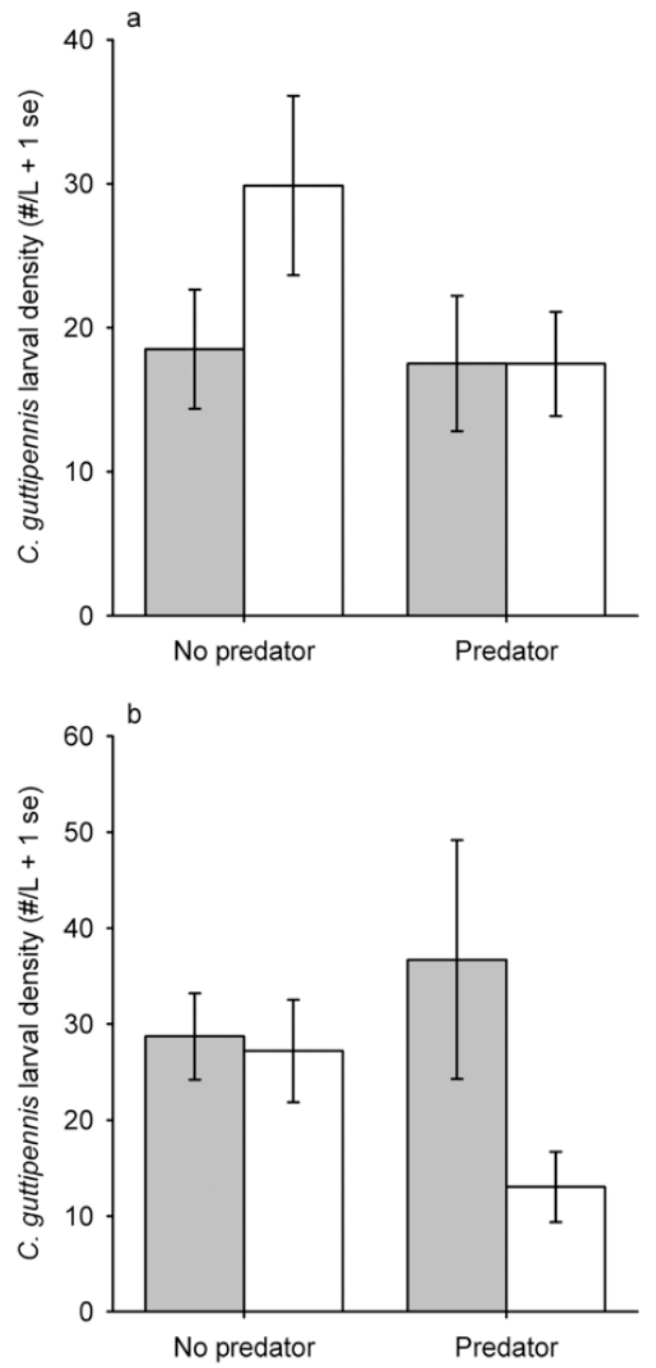

Fig. (3). Time-averaged densities of C. guttipennis in mesocosms during 2005 and 2007. a. 2005 densities. b. 2007 densities. Grey bars represent low leaf litter treatments and open bars represent high leaf litter treatments. Error bars represent 1 standard error.

over time. The decrease in late instar mosquitoes caused by T. rutilus corresponded to an overall decrease in mosquito populations as predicted; a finding consistent with previous studies (Bradshaw and Holzapfel 1983, Lounibos et al. 1987, Lounibos et al. 1997). The relationship of the predator to prey density and diversity also depended in part on predator density, as demonstrated by the regression analysis. Aedes triseriatus dominance thus declines in treeholes where $T$. rutilus is present and a majority of mosquito larvae are in late instars.

It is likely that this size selective and transitory effect of predation on A. triseriatus population sizes is due to complex interactions of predation, resources, habitat heterogeneity, overlapping life cycles, and rapid and repeated colonization of a variety of treeholes (Fish and Carpenter 1982, Lounibos 2001, Paradise et al. 2008). Rapid growth of larvae due to abundant food resources or low density of competitors allows larvae to quickly mature and effectively escape predators through emergence as adults. Prey populations also escape predation by inhabiting more treeholes within the metacommunity than those inhabited by $T$. rutilus (Bradshaw and Holzapfel 1983, Ellis et al. 2006, Paradise et al. 2008). For example, desiccation-tolerant eggs allow $A$. triseriatus to rapidly recolonize after drought (Bradshaw and Holzapfel 1983, Debboun and Hall 1992), allowing them to inhabit treeholes with less consistent water volume than that which T. rutilus would require (Steffan and Evenhuis 1981, Bradshaw and Holzapfel 1983, Lounibos et al. 1997, Lounibos 2001). Overlapping generations of A. triseriatus allow it to be present in most treeholes throughout the spring, summer and fall in several larval stages (Fish and Carpenter 1982, Debboun and Hall 1992). Our evidence suggests that early instar mosquitoes are less affected by predation by large T. rutilus larvae. When large, late-instar T. rutilus larvae emerge as adults, treeholes may be predator free for a period of time. Thus mosquitoes are able to maintain populations, regardless of the presence of T. rutilus.

Toxorhynchites rutilus densities were negatively related to densities of the midge C. guttipennis, but only in treeholes, so the effect could be correlative. Culicoides guttipennis breathes cutaneously, is commonly found in sediments of treeholes (Kruger et al. 1990, Barrera 1996, Paradise 2004), and is known to inhabit smaller containers, sometimes with very little standing water (Paradise 2004, Harlan and Paradise 2006). Midge populations thus exist in treeholes are not normally utilized by $T$. rutilus. Treeholes where both could exist would be long lasting treeholes with relatively greater water volumes; a situation that would lend itself to anoxic sediments. Thus, predation could occur when low dissolved oxygen forces larvae to spend time swimming above sediments, decreasing foraging efficiency and increasing risk of predation (Harlan and Paradise 2006). In mesocosms, we observed no effect of the predator on midges. Even low leaf litter may have provided sufficient refugia and allowed access to dissolved oxygen. Midges may also escape predation as mosquitoes do, by maintaining populations in many treeholes. Recolonization maintains populations, even as predation reduces densities, and in mesocosms dispersal between habitats could be high enough to maintain local populations (Lounibos et al. 1997, Chase and Leibold 2003). The lack of a predator manipulation effect, the preferences for treeholes with different conditions, and microhabitat preferences within treeholes lead us to conclude that there is very little impact on midges in the metacommunity at large.

The assertion that $T$. rutilus is a keystone predator relies on two premises: first, that the predator has a significant impact on populations of the dominant competitor, and second, that the reduction of this competitor leads to an increase in species diversity (Paine 1969, Kitching 2000). In treeholes, T. rutilus depressed populations of the dominant competitor (A. triseriatus) and the density of $T$. rutilus was positively associated with prey species diversity. These findings are in line with our predictions and support the keystone predator assertion. However, densities of the two most abundant prey types were also positively associated with prey diversity. Thus, even though $T$. rutilus presence occurred concurrently with increased species diversity, it does not appear that this was an indirect effect of their predation of the dominant prey species. This suggests that the connection between $T$. rutilus and species diversity is more correlative, such that both variables are caused by other factors in the habitat. These findings were reinforced in the 
mesocosm study. The mesocosm study was designed such that the habitat heterogeneity between treeholes was removed, i.e., water and other physical factors were held constant. Thus, if the presence of T. rutilus was the catalyst that caused this increase in species diversity (either directly or indirectly), the effect should have been observed in mesocosms as well. This was not the case. The combination of these two observations suggests that $T$. rutilus is not a keystone predator.

There are several explanations as to why T. rutilus would not cause keystone predation effects. First, the larval period of $T$. rutilus is very short, about $2-3$ weeks in summer, causing individuals to have a temporary impact on $A$. triseriatus populations (Steffan and Evenhuis 1981, Yanoviak 2001). It would take time and more constant levels of predation for rare species to respond to reduction of the dominant species, which could occur if multiple oviposition events led to the presence of overlapping T. rutilus larvae of different stages. But even the constant presence of predators in mesocosms did not produce a response in diversity, and we did not typically find $T$. rutilus in consecutive monthly treehole samplings (41 times out of a total of 448 possible consecutive samplings). Second, overlapping of generations of prey species produces stages that are differentially susceptible to predation (Fish and Carpenter 1982, Debboun and Hall 1992). Third, one of the dominant species, midges, was not affected in mesocosms. Fourth, niche partitioning may cause less competition between dominant and rare species (Mitchell and Rockett 1981, Bradshaw and Holzapfel 1983, Barrera 1996, Costanzo et al. 2005). Instead the species are limited by stochastic oviposition, abiotic factors, predation, and their own life cycles (Jenkins and Kitching 1990, Sota 1996, Srivastava and Lawton 1998, Paradise et al. 2008). The observed relationship between predation and diversity in treeholes is likely caused by similar factors favoring $T$. rutilus and prey populations. Toxorhynchites rutilus tends to occur in high densities under the same conditions conducive to higher diversity of the prey community.

Two conditions critical for the survival of larvae in treeholes are sufficient water and leaf litter (Fish and Carpenter 1982, Kitching 2000). Treehole species may have preferences for large treeholes with high water volumes and abundant leaf litter, perhaps perceived as containers with high organic matter content (Sota et al. 1994, Sota 1996). We did not observe consistent effects of either resource type on diversity. Other variables such as treehole size or water chemistry factors could be related to diversity through oviposition site selection (Steffan and Evenhuis 1981, Bradshaw and Holzapfel 1983, Sota 1996, Lounibos et al. 1997, Lounibos 2001, Mitchell and Rockett 1981). Although little is known about oviposition preferences of rare species in treeholes, selection should favor females that tend to choose more stable habitats (Bradshaw and Holzapfel 1983, Sota et al. 1994, Sota 1996). Larger treeholes with more water dry up less often (Sota 1996, Paradise 2004). Another possibility is that, in addition to being long-lasting, treeholes with larger openings and more water would also be easier for ovipositing females to find, and thus be more likely to be colonized (Sota 1996, Paradise 2004).
Taken as a whole, our evidence does not lend itself to the assertion that $T$. rutilus acts as a keystone predator, as suggested by Kitching (2000). As such, it becomes an interesting case study of a predator with dramatic effects on the most abundant prey species, but little effect on the community at large. Thus our findings speak to the complexity of even the simplest of systems and the utility of manipulative research in teasing apart direct and indirect effects. In the case of treeholes, the inconsistency in the effects of predation due to regional effects of the treehole metacommunity, the life cycles and habitat preferences of the insects, and the temporal dynamics of the predator and prey populations negated the overall effect of the predator. Rather, it appears that habitat characteristics play a more direct role in the dynamics of predator and prey populations. More research needs to be conducted, however, in order to determine the exact nature of the relationship between local habitat conditions and the regional dynamics of treehole metacommunities in the presence of a predator.

\section{ACKNOWLEDGEMENTS}

Duncan Berry, John Burkhart, Charlie Chrisawn, Justin Goldberg, Nicole Harlan, Lauren Harshaw, Ben Kegan, Ben Kittinger, Grace Metz, Lindsay Nakaishi, and Shawn Villalpando helped with field work and data management. Davidson College allowed us to use the Davidson College Ecological Preserve and the Davidson College Lake Campus. This research was supported by NSF-RUI grant DEB-0315208 to CJP, and several Davidson College Faculty Study and Research grants to CJP. The experiment conducted complies with the current laws of the United States of America.

\section{REFERENCES}

Abrams, PA, Menge, BA, Mittelbach, GG, Spiller, D \& Yodzis, P (1996) The role of indirect effects in food webs. In: Polis, GA \& Winemiller, KO (Eds), Food webs: integration of patterns and dynamics, New York, NY, Chapman and Hall, 371-95.

Barrera, R (1996) Species concurrence and the structure of a community of aquatic insects in treeholes. Journal of Vector Ecology, 21, 66-80.

Batzer, DP (1998) Trophic interactions among detritus, benthic midges, and predatory fish in a freshwater marsh. Ecology, 79, 1688-98.

Bradshaw, WE \& Holzapfel, CM (1983) Predator-mediated, nonequilibrium coexistence of tree-hole mosquitoes in south eastern North America. Oecologia, 57, 239-56.

Chase, JM \& Leibold, MA (2003) Ecological niches: linking classical and contemporary approaches, University of Chicago Press, Chicago, IL.

Costanzo, KS, Kesavaraju, B \& Juliano SA (2005) Condition-specific competition in container mosquitoes: the role of noncompeting lifehistory stages. Ecology, 86, 3289-95.

Debboun, M \& Hall, RD (1992) Mosquitoes (Diptera: Culicidae) sampled from treeholes and proximate artificial containers in central Missouri. Journal of Entomological Science, 27, 19-28.

Ellis, AM, Lounibos, LP \& Holyoak, M (2006) Evaluating the long-term metacommunity dynamics of tree hole mosquitoes. Ecology, 87, 2582-90.

Fish, D \& Carpenter, SR (1982) Leaf litter and larval mosquito dynamics in tree-hole ecosystems. Ecology, 63, 283-8.

Harlan, NP \& Paradise, CJ (2006) Do habitat size and shape modify abiotic factors and communities in artificial treeholes? Community Ecology, 7, 211-22.

Jenkins, B \& Kitching, RL (1990) The ecology of water-filled treeholes in Australian rainforests: food web reassembly as a measure of community recovery after disturbance. Australian Journal of Ecology, 15, 199-205. 
Jost, L (2006) Entropy and diversity. Oikos 113, 363-75.

Juliano, SA (1989) Geographic variation in vulnerability to predation and starvation in larval treehole mosquitoes. Oikos, 56, 99-108.

Juliano, SA \& Gravel, ME (2002) Predation and the evolution of prey behavior: an experiment with treehole mosquitoes. Behavioral Ecology, 13, 301-11.

Kitching, RL (2000) Food webs and container habitats: the natural history and ecology of phytotelmata. Cambridge University Press, Cambridge, UK.

Kneitel, JM \& Miller, TE (2002) Resource and top-predator regulation in the pitcher plant (Sarracenia purpurea) inquiline community. Ecology, 83, 680-8.

Kruger, EL, Pappas, LG \& Pappas, CD (1990) Habitat and temporal partitioning of tree hole Culicoides (Diptera: Ceratopogonidae). Journal of the American Mosquito Control Association, 6, 390-3.

Lounibos, LP (2001) Boom-or-bust development of a predatory mosquito in temporary aquatic habitats. Israel Journal of Zoology, 47, 433-44.

Lounibos, LP, Frank, JH, Machado-Allison, CE, Ocanto, R \& Navarro, JC (1987) Survival, development and predatory effects of mosquito larvae in Venezuelan phytotelmata. Journal of Tropical Ecology, 3, 221-42.

Lounibos, LP, Escher, RL, Nishimura, N \& Juliano, SA (1997) Long-term dynamics of a predator used for biological control and decoupling from mosquito prey in a subtropical treehole ecosystem. Oecologia, $111,189-200$.

Manly, BFJ (1997) Randomization, bootstrap and Monte Carlo methods in biology. Chapman and Hall, London, UK.

Mitchell, L \& Rockett, CL (1981) An investigation on the larval habitat of 5 species of tree-hole breeding mosquitoes (Diptera: Culicidae). The Great Lakes Entomologist, 14, 123-9.

Paine, RT (1969) The Pisaster tegula interaction: prey patches, predator food preference, and intertidal community structure. Ecology, 50, 950-61.

Paradise, CJ (2004) Relationship of water and leaf litter variability to insects inhabiting treeholes. Journal of the North American Benthological Society, 23, 793-805.
Paradise, CJ, Blue, JD, Burkhart, JQ, Goldberg, J, Harshaw, L, Hawkins, KD, Kegan, B, Kittinger, B, Krentz, T, Smith, L \& Villalpando, S (2008) Local and regional factors influence the structure of treehole metacommunities. BMC Ecology, 8, 22.

Peacor, SD \& Werner, EE (2001) The contribution of trait-mediated indirect effects to the net effects of a predator. Proceedings of the National Academies of Science, 98, 3904-8.

Rosemond, AD, Pringle, CM, Ramirez, A \& Paul, MJ (2001) A test of topdown and bottom-up control in a detritus-based food web. Ecology, 82, 2279-93.

Schmitz, O.J., \& Suttle, K.B. (2001) Effects of top predator species on direct and indirect interactions in a food web. Ecology, 82, 207281.

Sota, T (1996) Effects of capacity on resource input and the aquatic metazoan community structure in phytotelmata. Researches on Population Ecology, 38, 65-73.

Sota, T, Mogi, M \& Hayamiza, E (1994) Habitat stability and the larval mosquito community in treeholes and other containers on a temperate island. Researches on Population Ecology, 36, 93-104.

Srivastava, DS \& Lawton, JH (1998) Why more productive sites have more species: experimental test of theory using tree-hole communities. American Naturalist, 152, 510-29.

Steffan, WA \& Evenhuis, NL (1981) Biology of Toxorhynchites. Annual Review of Entomology, 26, 159-81.

von Ende, C (2001) Repeated-measures analysis: growth and other timedependent measures. In: Scheiner, SM \& Gurevitch, J (Eds) Design and analysis of ecological experiments, University Press: Oxford, UK, Oxford 134-57.

Yanoviak, SP (1999) Effects of leaf litter species on macroinvertebrate community properties and mosquito yield in Neotropical tree hole microcosms. Oecologia, 120, 147-55.

Yanoviak, SP (2001) Predation, resource availability, and community structure in Neotropical water-filled tree holes. Oecologia, 126, 125-33.

Received: August 17, 2009

(C) Smith et al.; Licensee Bentham Open.

This is an open access article licensed under the terms of the Creative Commons Attribution Non-Commercial License (http://creativecommons.org/licenses/by$\mathrm{nc} / 3.0 /$ ), which permits unrestricted, non-commercial use, distribution \& reproduction in any medium, provided the work is properly cited. 